\title{
Influence of the Commercial Mouthwashes on the Corrosion Behaviour of Dental Alloy
}

\author{
Denise Pupim ${ }^{a}$, Raniel Fernandes Peixoto ${ }^{b}$ (D), Ana Paula Macedo ${ }^{a}$ (D), Regina Guenka Palma-Dibb ${ }^{a}$, \\ Maria da Gloria Chiarello de Mattos ${ }^{a}$, Rodrigo Galo ${ }^{a}$ (D) \\ ${ }^{a}$ Universidade de São Paulo, Faculdade de Odontologia, Departamento de Prótese e Materiais \\ Dentários, Ribeirão Preto, SP, Brasil. \\ ${ }^{b}$ Universidade Federal do Ceará, Faculdade de Farmácia, Odontologia e Enfermagem, Departamento \\ de Odontologia Restauradora, Fortaleza, CE, Brasil.
}

Received: July 26, 2021; Revised: November 9, 2021; Accepted: December 13, 2021.

\begin{abstract}
Dental alloys are widely used in fabrication of removable partial dentures, particularly as a dental framework. The present study aimed at studying the effect of the commercial mouthwashes on the corrosion behavior of the $\mathrm{Co}-\mathrm{Cr}$ dental casting alloy. Corrosion behavior was investigated in alcoholfree and alcohol-containing mouthwashes added to artificial saliva solutions at room temperature by electrochemical tests recorded the open circuit potential (OCP) and current density, after the surface analysis of the samples was performed. During the early 250 s, the OCP values showed significant changes, with the exception of one test group containing alcohol, where potential decreased continuously during the test, which also recorded the highest current density, different from the other groups. It was observed that the presence of alcohol increased the current density and the corrosion process in this alloy and the mouthwashes had more aggressive action in specimens submitted to solutions with alcohol in the composition.
\end{abstract}

Keywords: Dental alloys; electrochemical corrosion; commercial mouthwashes; roughness.

\section{Introduction}

The material most commonly used to produce removable partial dentures and its frameworks is the Co-Cr alloys. These alloys have also been used to manufacture implant components ${ }^{1}$. However, the oral environment promotes the metal degradation, requiring good corrosion-resistant properties of these metallic materials ${ }^{2}$. In the oral cavity, dental alloys are subject both to the action of mechanical forces and to chemical agents from the bacterial biofilm and saliva ${ }^{3-5}$, as well as products used by patients for oral hygiene ${ }^{6-8}$.

Co-Cr alloys have been used in dentistry since 1930s, when they replaced the gold alloys for partial denture frameworks, mainly due to their good physical and mechanical properties $^{9-11}$, high biocompatibility ${ }^{12-13}$, excellent corrosion resistance ${ }^{14}$ and low cost $\mathrm{t}^{9,12,14}$. This alloy is corrosion-resistant in different solutions, such as artificial saliva and physiological environments ${ }^{9}$, due formation of a protective oxide layer, although alterations on the corrosion-resistant properties of Co-Cr alloys may occur ${ }^{15}$ when the material is exposed to an aggressive medium such as the oral cavity, associated to the presence of dental toothpastes and mouthwashes or fluorides.

Mouthwashes are used as auxiliary solution in oral hygiene and are indicated to improve cleaning of removable partial dentures ${ }^{4,16}$. Studies have shown that fluoride-based mouthwashes affect the electrochemical behavior of titanium and commercially pure titianium-based alloys ${ }^{7,14}$. Schiff et al. ${ }^{4}$, studied the corrosion behavior of orthodontic brackets in three commercial fluoride containing mouthwashes and

*e-mail: rogalo@forp.usp.br mentioned that, Co-Cr alloy did not exhibited a significant corrosion damage.

The corrosion process is described as the metal degradation by the aggressive action of the oral environment and other fluids ${ }^{17}$. The corrosion-resistant properties of metal alloys are dependent of factors related to the alloy composition, surface roughness, degree of oxidation and acidity $(\mathrm{pH})$, temperature, presence of corrosion inhibitors and microorganisms ${ }^{18}$.

According to Bezzon et al. ${ }^{19}$, changes in the surface roughness of prosthetic devices increase the plaque adhesion, allowing the incidence of caries in abutment and remaining teeth, gingival and periodontal disease, can accelerate the biocorrosion process, creating retentive niches. Additionally, the growth of biofilm on metallic surface is results of an accumulative process that had begun immediately after the contact between the metal and the environment ${ }^{20}$, being the oral environment or solutions used to improve the oral and prosthetic hygiene. The plaque adhesion is not only dependent of the surface roughness, but also the interface free energy to microbial attachment and the $\mathrm{pH}$ of the medium ${ }^{12,21,22}$. According to Correa et al. ${ }^{5}$, the mouthwashes and fluoride solutions can cause corrosion increasing the surface roughness, allowing the attachment of microorganisms on the alloy surface, and being the roughness an important factor in setting and bacterial colonization.

Given the importance of prosthetic hygiene for the longevity of the treatment and maintenance of patients' health, it were analyzed on this study the microstructural characteristics, changes on the surface roughness and corrosion resistance of Co-Cr alloys immersed in mouthwash solutions and artificial 
saliva. The null hypothesis was that there are no differences on corrosion resistance of a $\mathrm{Co}-\mathrm{Cr}$ dental alloy in contact with mouthwashes, and the action of these solutions cannot influence on surface roughness of the alloy.

\section{Materials and Methods}

\subsection{Materials and specimen preparation}

The chemical composition (in wt.\%) of the alloy was Co (61\%), Cr (24\%), W (8\%), Mo (2,5\%), Nb (1\%), Mn (1\%), $\mathrm{Si}(1 \%)$ and $\mathrm{Fe}(1 \%)$. Co-Cr samples with the following dimensions: $13 \mathrm{~mm}$ diameter and $2 \mathrm{~mm}$ thickness (DFS, Landenstrabe, Riedemburg) were processed by lost wax technique by casting using conventional flame fusion technique followed by injection with centrifugation.

Prior to testing, the samples were ground wet until \# 2000-grit silicon carbide papers and followed by two polishing stages with $3-\mu \mathrm{m}$ and $1-\mu \mathrm{m}$ grit diamond suspension (Struers, Glasgow, UK). After polishing, the samples were ultrasonic cleaned for 15 minutes in alcohol isopropyl followed by 10 minutes in distilled water. Samples were dried using a hot air gun. In order to obtain the similar surface conditions, each sample was kept in desiccators for $24 \mathrm{~h}$ before starting the corrosion tests.

Specimens were divided into 5 groups $(n=8)$ according to the mouthwash-containing solution where the samples were immersed during the experiment (Table 1). Four different commercially available mouthwashes were used in corrosion tests, together with Fusayama's artificial saliva, and the control group was used Fusayama artificial solution (AS); consisted of $\mathrm{NaCl}\left(0.4\right.$ g.L $\left.\mathrm{L}^{-1}\right), \mathrm{KCl}\left(0.4\right.$ g.L $\left.\mathrm{L}^{-1}\right), \mathrm{CaCl}_{2} .2 \mathrm{H}_{2} \mathrm{O}\left(0.795\right.$ g.L $\left.\mathrm{L}^{-1}\right)$, $\mathrm{Na}_{2} \mathrm{~S} .9 \mathrm{H}_{2} \mathrm{O}\left(0.005\right.$ g. $\left.\mathrm{L}^{-1}\right), \mathrm{NaH}_{2} \mathrm{PO}_{4} .2 \mathrm{H}_{2} \mathrm{O}\left(0.65\right.$ g.L $\left.\mathrm{L}^{-1}\right)$, and Urea $\left(1\right.$ g. $\left.\mathrm{L}^{-1}\right)$. The solution was prepared daily with pure chemical products (Sigma Chemical Company) added to distilled water and presented a $\mathrm{pH}$ of approximately 5.5 , measured by a $\mathrm{pH}$ meter (EUTECH Instruments $\mathrm{pH} 510$ ), in order to assess the corrosive action of these solutions when in contact with the Co-Cr dental alloy. Tests were performed at $37 \pm 1^{\circ} \mathrm{C}$ on an oven controlled by thermostat simulating the body temperature.

\subsection{Electrochemical measurements}

The electrochemical measurements were performed using a potentiostast (PGP201 Radiometer Analytical, Copenhagen, Denmark) controlled by the Voltamaster-4 Software (Voltamaster, Radiometer Analytical, Copenhagen, Denmark), running on a computer to perform the corrosion measurements.
The sample area was defined by an O-ring exposing, an area of approximately $15,07 \mathrm{~mm}^{2}$. Potentials were measured against a standard calomel electrode - SCE (B20B110, Radiometer Analytical, Copenhagen, Denmark) and a platinum electrode as a counter, with an exposed area of $1 \mathrm{~cm}^{2}$ (wire B35M110, Radiometer Analytical, Copenhagen, Denmark).

For each specimen, the open circuit potential (OCP) was recorded for 3600 seconds ( 1 hour) in order to stabilize the surface at $O C P$. Thus, the potentiodynamic polarization curves were carried out from $-500 \mathrm{mV}$ to $+1000 \mathrm{mV}$ vs. $\mathrm{SCE}$ at scanning rate of $2 \mathrm{mV} / \mathrm{s}$ and the $\mathrm{i}_{\text {pass }}$ measured.

\subsection{Surface topography analysis}

The surface analysis of the samples was performed using a confocal laser microscope (LEXT OLS4000 Olympus Corporation, Tokyo, Japan) immediately after the electrochemical tests for characterization of possible irregularities and wear caused by the solutions on the samples surface. Comparisons of the images obtained among the Co-Cr alloy surfaces were performed through the pre- and post- corrosion analysis of each tested solution. The disks did not require any preparation for analysis on this equipment.

In order to understand the changes on alloy surface promoted by the corrosion process, a surface roughness parameter ( $\mathrm{Sa}$ - arithmetic mean of the surface roughness) was investigated through the confocal laser microscope, $5 x$ lens, with final magnification of $117 x$, at the end of electrochemical tests, in order to quantify the wear caused by the solutions on the sample surface.

Each specimen was individually placed in the center of equipment and the laser beam was positioned on the center of sample. Six measurements of surface roughness were performed on each sample, using cut off $(\lambda c) 80 \mu \mathrm{m}$, three readings on the exposed area and three in the control area. Measurements were taken at $\mathrm{Sa}$ parameter corresponding to $R a$ parameter of conventional perfilometer. An average of each region was used to analyze the data obtained.

The images used to measure the surface roughness were used to make a qualitatively morphological analysis and to analyze the three-dimensional topography of each specimen.

\subsection{Statistical analysis}

The data of corrosion kinetics and surface roughness were separately tested. For corrosion test, all data were statistically analyzed using one-way analysis of variance (ANOVA) and multiple comparisons test (Turkey-Kramer post hoc test) to examine the corrosion effect of the solutions

Table 1. Different mouthwashes used for each test group.

\begin{tabular}{clll}
\hline Group & \multicolumn{1}{c}{ Description } & \multicolumn{1}{c}{ Brand } & \multicolumn{1}{c}{ Solution } \\
\hline Group 1 & Control Group & Fusayama's solution & $100 \mathrm{~mL}$ of artificial saliva \\
\hline Group 2 & $\begin{array}{l}\text { Listerine }{ }^{\circledR} \text { alcohol- } \\
\text { containing }\end{array}$ & Johnson \& Johnson, São Paulo, SP, Brazil & $\begin{array}{l}50 \mathrm{~mL} \text { of mouthwash }+50 \mathrm{~mL} \text { of artificial } \\
\text { saliva }\end{array}$ \\
\hline Group 3 & Listerine $^{\circledR}$ alcohol-free & Johnson \& Johnson, São Paulo, SP, Brazil & $\begin{array}{l}50 \mathrm{~mL} \text { of mouthwash }+50 \mathrm{~mL} \text { of artificial } \\
\text { saliva }\end{array}$ \\
\hline Group 4 & Plax $^{\circledR}$ alcohol-containing & $\begin{array}{l}\text { Colgate and Palmolive Indústria e } \\
\text { Comércio, São Paulo, SP, Brazil }\end{array}$ & $\begin{array}{l}50 \mathrm{~mL} \text { of mouthwash }+50 \mathrm{~mL} \text { of artificial } \\
\text { saliva }\end{array}$ \\
\hline Group 5 & Plax $^{\circledR}$ alcohol-free & $\begin{array}{l}\text { Colgate and Palmolive Indústria e } \\
\text { Comércio, São Paulo, SP, Brazil }\end{array}$ & $\begin{array}{l}50 \mathrm{~mL} \text { of mouthwash }+50 \mathrm{~mL} \text { of artificial } \\
\text { saliva }\end{array}$ \\
\hline
\end{tabular}


on the Co-Cr dental alloy. Data were analyzed by ANOVA for $i_{\text {pass }}$ variation, in addition to the multiple comparisons test (Bonferroni) in order to examine the change in the alloy surface roughness in contact with the mouthwashes.

The Statistical Package for the Social Sciences (version 17.0, SPSS Inc, Chicago, IL, USA) was used for the statistical analysis. For all tests, a 5\% level of significance $(\mathrm{p}<0.05)$ was adopted.

\section{Results}

The open circuit potential curves $(O C P)$ of $\mathrm{Co}-\mathrm{Cr}$ alloy immersed on each experimental group are shown in Figure 1 and Table 2 shows the mean of $O C P$ and current density $\left(i_{\text {corr }}\right)$ recorded during the experiment. The more positive $O C P$ values were recorded in group $4(-172.75 \pm 32.85 \mathrm{mV})$ and group $5(-179.13 \pm 60.80 \mathrm{mV})$, being significantly more positive than control group - group $1(-256.63 \pm 48.93 \mathrm{mV})$. No significance differences in the corrosive effect of immersion solutions were found in comparative analysis between group 2 and $3(p>0.05)$.

The potentiodynamic values and curves obtained for each group are shown on Figure 2. All curves presented similar features. From the potentiodynamic curves, the $i_{\text {corr }}$ and $i_{\text {pass }}$ were determined. Results of one-way ANOVA showed that some mouthwashes had a significant influence on the $i_{\text {corr }}$ (Table 2).

The comparison of current density $\left(i_{\text {corr }}\right)$ among the groups shows that group 1 presented similar values $(\mathrm{p}>0.05)$

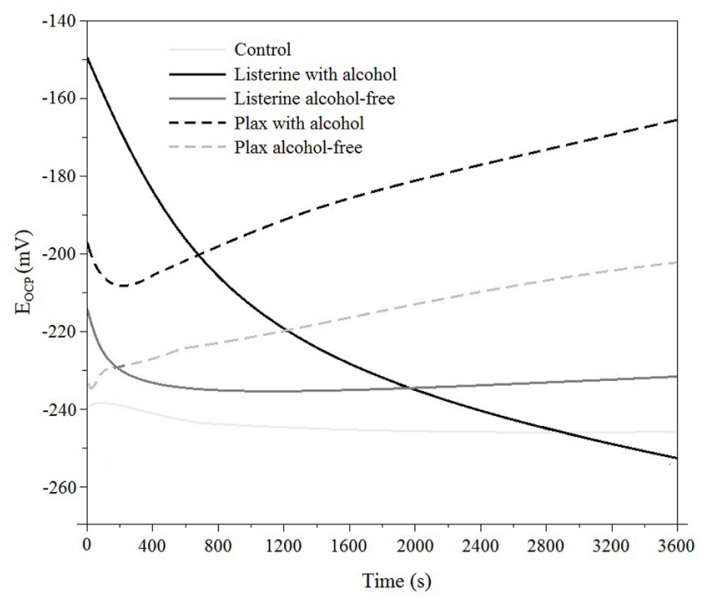

Figure 1. Potentiostatic curves for $\mathrm{Co}-\mathrm{Cr}$. to group 3, group 4 and group 5. However, group 2 presented the higher tendency to corrode $\left(5.791 \pm 1.54 \mu \mathrm{A} / \mathrm{cm}^{2}\right)$. Regarding the values of current passivation $\left(i_{\text {pass }}\right)$, where no statistically significant difference was found among the tested groups, but the dates denote mass loss on the metal surface (anodic dissolution). $i_{\text {pass }}$ values, although not statistically significant, indicated greater current required for development of passive film layer at group 1. Groups 3 and 4 showed the best values of current density $\left(0.092 \mu \mathrm{A} / \mathrm{cm}^{2}\right.$ and $0.082 \mu \mathrm{A} / \mathrm{cm}^{2}$, respectively), and these values were closer to group $1\left(0.067 \pm 0.013 \mu \mathrm{A} / \mathrm{cm}^{2}\right)$.

The microstructures obtained after the potentiodynamic tests are different for each solution analyzed. Regarding the surface morphological analysis, performed with the confocal laser microscope, was found different surface morphology for each groups studied, and only in areas unexposed to the solutions the surface characteristics were similar (Figure 3). In the left column are the images of unexposed areas to the action of mouthwashes, while the right column represents the exposed areas of the groups 1, 2, 3, 4 and 5, respectively.

The means of $S a$ values are shown on Table 3. Data did not show statistically significant differences $(p>0.05)$ on surface roughness values of the tested groups when the exposed and unexposed areas were compared. When the exposed area was analyzed, group $2(0.250 \pm 0.089 \mathrm{um})$ and group $3(0.420 \pm 0.137 \mathrm{um})$ were lower than the other groups $(p<0.05)$, while group 1, 3 and group 5 were similar $(p>0.05)$. When performed intra-group comparison, no differences were observed between exposed area and unexposed area for

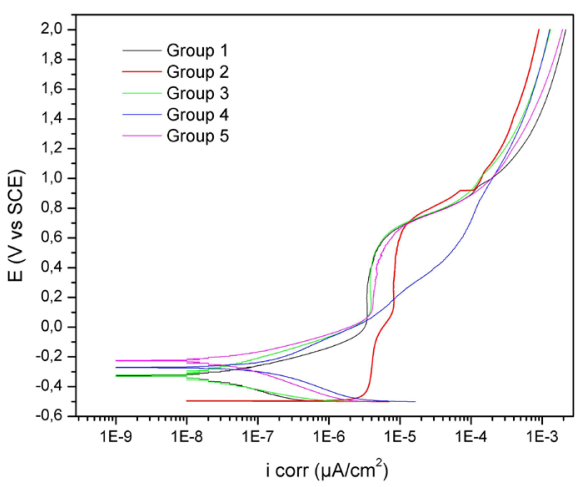

Figure 2. Potentiodynamic polarization curves for $\mathrm{Co}-\mathrm{Cr}$ alloy in commercial mouthwashes (Group 1) Co-Cr Fusayama's saliva; (Group 2) Co-Cr Listerine $($ alcohol-containing; (Group 3) Co-Cr Listerine $₫$ alcohol-free; (Group 4) Co-Cr Plax $₫$ alcohol-containing (Group 5) CoCr Plax ${ }^{\circledR}$ alcohol-free.

Table 2. Corrosion parameters obtained from potentiodynamic polarization curves of $\mathrm{CoCr}$ alloy in different mouthwash solutions and artificial saliva (means and standard deviation).

\begin{tabular}{cccc}
\hline Solution & $\mathbf{E}_{\text {ocp }}(\mathbf{m V})$ & $\mathbf{i}_{\text {pass }}\left(\boldsymbol{\mu A} / \mathbf{c m}^{2}\right)$ & $\mathbf{i}_{\text {corr }}\left(\boldsymbol{\mu} \mathbf{A} / \mathbf{c m}^{\mathbf{2}}\right)$ \\
\hline Group 1 & $-256.625 \pm 48.925 \mathrm{~A}$ & $4.973 \pm 0.073$ & $0.067 \pm 0.013 \mathrm{~A}$ \\
\hline Group 2 & $-233.750 \pm 65.869 \mathrm{AB}$ & $4.543 \pm 0.588$ & $5.791 \pm 1.546 \mathrm{~B}$ \\
\hline Group 3 & $-221.375 \pm 30.687 \mathrm{AB}$ & $4.914 \pm 0.134$ & $0.459 \pm 0.275 \mathrm{~A}$ \\
\hline Group 4 & $-172.759 \pm 32.854 \mathrm{~B}$ & $4.701 \pm 0.908$ & $0.092 \pm 0.101 \mathrm{~A}$ \\
\hline Group 5 & $-179.125 \pm 60.796 \mathrm{~B}$ & $4.936 \pm 0.193$ & $0.082 \pm 0.056 \mathrm{~A}$ \\
\hline
\end{tabular}

\footnotetext{
* Capital letters, indicating a statistically significant difference $(\mathrm{p}<0.05)$.
} 

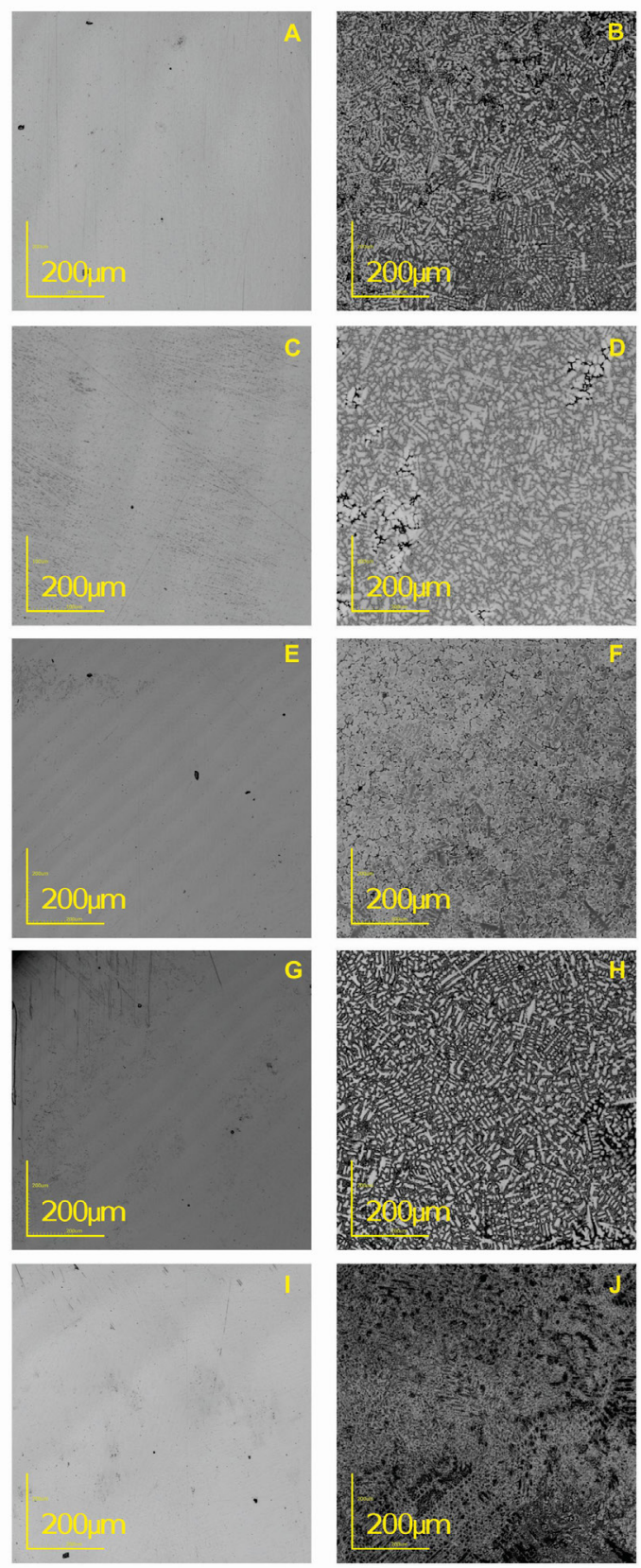

Figure 3. Representative micrographs of corrosion superficial. A) Co-Cr before Fusayama's saliva; B) Co-Cr after Fusayama's saliva; C) Co-Cr before Listerine $\left(\mathbb{R}\right.$ alcohol-containing; D) Co-Cr after Listerine ${ }^{\circledR}$ alcohol-containing; E) Co-Cr before Listerine ${ }^{\circledR}$ alcohol-free; F) Co-Cr after Listerine ${ }^{\circledR}$ alcohol-free; G) Co-Cr before Plax ${ }^{\circledR}$ alcohol-containing; H) Co-Cr after Plax ${ }^{\circledR}$ alcohol-containing; I) Co-Cr before Plax ${ }^{\circledR}$ alcohol-free and J) CoCr after Plax ${ }^{\circledR}$ alcohol-free.

Table 3. Surface roughness mean and significance interval (95\%) of CoCr alloy tested in different mouthwashes. pre and post-corrosion areas.

\begin{tabular}{ccc}
\hline Solução & Pre-corrosion & Post-corrosion \\
\cline { 2 - 3 } & Média (DP) & Média (DP) \\
\hline Control group & $0.108(0.039) \mathrm{Aa}$ & $0.736(0.086) \mathrm{Ab}$ \\
\hline Listerine $^{\circledR}$ alcohol-containing & $0.141(0.071) \mathrm{Aa}$ & $0.250(0.089) \mathrm{Ba}$ \\
\hline Listerine $^{\circledR}$ alcohol-free & $0.082(0.006) \mathrm{Aa}$ & $0.420(0.137) \mathrm{Bb}$ \\
\hline Plax $^{\circledR}$ alcohol-containing & $0.075(0.015) \mathrm{Aa}$ & $0.701(0.111) \mathrm{Ab}$ \\
\hline Plax $^{\circledR}$ alcohol-free & $0.085(0.017) \mathrm{Aa}$ & $0.850(0.118) \mathrm{Ab}$ \\
\hline
\end{tabular}

* ANOVA complemented by the Bonferroni test for multiple comparisons. * Capitalization (in the same column) and lower (on the same line) values. indicating a statistically significant difference $(\mathrm{p}<0.05)$. 
surface roughness in the group 2, while in the other groups statistically significant difference was found $(\mathrm{p}<0.05)$.

\section{Discussion}

The mouthwashes had significant influence on the obtained electrochemical values, and the data supported rejecting the stated null hypothesis. Mouthwashes used in the general population may influence the corrosion of $\mathrm{Co}-\mathrm{Cr}$ prosthetic frameworks. ${ }^{23}$

As a general tendency, in the control group (group 1), the potential remained constant during almost whole test, but a sight change in potential was observed in the first seconds (up to $800 \mathrm{~s}$ ). In contrast, group 2 showed great reduction in potential value $(-233.75 \mathrm{mV})$ after 1 hour in OCP, indicating an increased tendency to corrosion, as well as group $3(-221.37 \mathrm{mV})$ with the similar behavior. These results may be related to the mouthwash composition, which could have negatively influenced the formation of protective film due the presence of alcohol. Groups 4 and 5 showed the best electrochemical behavior, where the values were similar to the control group (group 1), increasing the potential and, consequently, decreasing the tendency to corrosion $(-172.75 \pm 32.85 \mathrm{mV}$ and $-179.12 \pm 60.79 \mathrm{mV}$, respectively). The results shows that the initial changes suggest a reorganization of the surface when in contact with the solution. The ion exchange with the electrolyte produces a protective film on the surface, so that there is the formation of a protective layer make the metal being more resistant to corrosion. It was found that the electrochemical behavior was affected by the mouthwash. The passive behavior of the alloy could be due to the oxide protective film formed on the surface, rich in chromium composition, which changes the composition and thickness according to the potential and time,${ }^{24}$ associated to reduction of the active surface area during the immersion time ${ }^{16}$.

The anodic reaction (Figure 2) is assumed to be oxygen reduction and it can be observed when the current density in the cathodic area decreases when applied potential is less negative. The anodic area shows two passive areas, first at $\sim 0.6 \mathrm{~V}$ and the other when the potential is bigger than $\sim 0.6 \mathrm{~V}$.

High current density at the correspondent potential indicates a higher alloy corrosion rate. Smaller current changes are related to the consecutive formation and repassivation of micro size pits. These metastable pits may be caused by the fluoride or presence of chloride in mouthwashes and cleansers and the difference presented by mouthwash containing alcohol can be explained by the highly acidic character of these solutions that may affect the oxidation and reduction reactions and may change the surface characteristics.

The boundaries of the grains were affected more quickly than the grains, causing dark groves along the sample surface. The dark areas can be corresponding to the zones with higher Co concentrations, while the lighter areas can be indicating higher $\mathrm{Cr}$ concentrations, suggesting better corrosion resistance due to the formation of chromium oxidebased protective film $\left(\mathrm{Cr}_{2} \mathrm{O}_{3}\right) \cdot{ }^{10}$ However, group 1 showed a different pattern, following the same surface distribution of the group 2, suggesting a greater tendency to corrode for

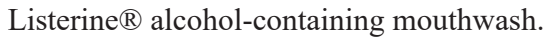

A more stable and uniform oxide layer is expected in more homogeneous matrices that in highly dendritic structures, providing greater corrosion protection ${ }^{21}$, which does not seem to occur in groups alcohol-containing (group 2 and group 4).

The formation of a passive layer of chromium oxide-based on the surface of $\mathrm{Co}-\mathrm{Cr}$ alloy is responsible for its superior corrosion resistance when compared to other alloys $\mathrm{s}^{11-12,14,19}$. The addition of chromium and molybdenum are related to improvement of alloys corrosion resistance ${ }^{3}$. The lighter areas on Figure 3 indicate areas of face-centered cubic more resistant to attack caused by the environment which the alloys were exposed, while the darker areas correspond to interdendritic regions, with body-centered hexagonal structure, more susceptible to corrode. This finding is confirmed by the better results of $i_{\text {pass }}$ recorded for group 2, indicating lower resistance of the passive film against corrosion, beyond the group have a higher concentration of interdendritic areas.

When analyzing the surfaces after immersion, it was found that mouthwashes had more aggressive action in specimens submitted to solutions with alcohol in the composition (group 2 and 4), although in all groups has been some superficial changes. Considerable evidence of surface corrosion represented by surface damage can be seen at the surface of samples in contact with mouthwashes.

This fact can be explained by the greater deposition of corrosion products by the solution during surface scan performed by application of electrochemical potential, which could have reduced the surface roughness besides to promote breakdown of the oxide layer of the sample surface, making them more susceptible to the corrosive action. Some changes to the microstructure may also be the result of incipient melting carbides during the casting period, increasing the potential for corrosion of the alloys ${ }^{25}$.

The increase in surface roughness has clinical implications for dentistry, mainly because contribute to bacterial colonization, adhesion of microorganisms and maintenance of biofilms on surfaces even after the prosthesis has been cleaned ${ }^{6,19,22}$.

Analysis performed by micrograph of $\mathrm{Co}-\mathrm{Cr}$ corrosion behavior usually consists of general dissolution of specific matrix, with preferential attack of intergranular boundaries, being the behavior independent of the microstructure ${ }^{26}$. A more stable and uniform oxide layer is expected in more homogeneous matrices than in highly dendritic structures, providing greater corrosion protection, which does not seem to occur in groups alcohol-containing.

According to Garcia et al. ${ }^{3}$, in a similar study, the surfaces of Co-Cr alloys immersed in commercial sanitizers had lower values of surface roughness when compared to the results found for the manipulated sanitizers and water, probably due to the effectiveness of these products in removing the formed film from the alloy surface. In addition, Bezzon et al. ${ }^{19}$, point out that the casting flame of oxygen-acetylene, as used in this study, can cause alloy overheating, and the use of flame oxidation zone at low temperatures in oxygen-rich environment can increase the oxidation by embedding elements and gases in the air, resulting in an increase in surface roughness and porosity of the final framework.

The plaque control and proper hygiene are extremely important especially when few remaining teeth become 
pillars of removable dentures ${ }^{20,21}$. The biofilm control can prevent or avoid the microbial adhesion ${ }^{6}$. Thus, the use of complementary cleaning products is indicated seeking for the biofilm control, although the immersion of the metal frameworks in solutions containing cleansers can cause corrosion or surface tarnish ${ }^{3}$.

\section{Conclusion}

It may be concluded based on the surface roughness values, topography and corrosion measurements that due to the lower rate of corrosion and the closer results obtained in Control Group, the mouthwashes alcohol-free are more suitable than those alcohol-containing. Therefore, patients using Co-Cr frameworks should avoid mouthwashes and cleansers containing alcohol to clean the prosthesis due the tendency to corrode and the increase on surface roughness.

\section{References}

1. Hollweg H, Jacques LB, Moura MS, Bianco VC, Souza EAC, Rubo JH. Deformation of implant abutments after framework connection using strain gauges. J Oral Implantol. 2012;38(2):12532.

2. Geckili O, Bilhan H, Bilgin T, von Fraunhofer JA. The effect of urea on the corrosion behavior of different dental alloys. Indian J Dent Res. 2012;23(1):75-9.

3. Garcia RCMR, Souza JA Jr, Rached RN, Cury AADB. Effect of denture cleansers on the surface roughness and hardness of a microwave-cured acrylic resin and dental alloys. J Prosthodont. 2004;13(3):173-8.

4. Schiff N, Dalard F, Lissac M, Morgon L, Grosgogeat B. Corrosion resistance of three orthodontic brackets: a comparative study of three fluoride mouthwashes. Eur J Orthod. 2005;27(6):541-9.

5. Correa CB, Pires JR, Fernandes-Filho RB, Sartori R, Vaz LG. Fatigue and Fluoride Corrosion on Streptococcus mutans adherence to titanium-based implant/component surfaces. J Prosthodont. 2009;18(5):382-7.

6. Davi LR, Felipucci DNB, Souza RF, Bezzon OL, Lovato-Silva $\mathrm{CH}$, Pagnano VO, et al. Effect of denture cleansers on metal ion release and surface roughness of denture base materials. Braz Dent J. 2012;23(4):387-93.

7. Toniollo MB, Galo R, Macedo AP, Rodrigues RCS, Ribeiro RF, Mattos MGC. Effect of fluoride sodium mouthwash solutions on cpTi: evaluation of physicochemical properties. Braz Dent J. 2012;23(5):496-501.

8. Parizi MTT, Taheri S, Amini P, Afshar MK. Evaluation of denture hygiene among removable denture wearers referred to clinics of Kerman, Iran. J Oral Health Oral Epidemiol. 2013;2(1):44-8.

9. Kedici SP, Ciksüt AA, Kiliçarlslan MA, Bayramoglu G, Gökdemir K. Corrosion behavior of dental metals and alloys in different media. J Oral Rehabil. 1998;25(10):800-8.

10. Galo R, Ribeiro RF, Rodrigues RCS, Rocha LA, Mattos MGC. Effects of chemical composition on the corrosion of dental alloys. Braz Dent J. 2012;23(2):141-8.
11. Luo X, Li X, Sun Y, Dong H. Tribocorrosion behavior of S-phase surface engineered medical grade CoCr alloy. Wear. 2013;302(1-2):1615-23.

12. Nogués L, Martinez-Gomis J, Molina C, Peraire M, Salsench $\mathrm{J}$, Sevilla $\mathrm{P}$, et al. Dental casting alloys behavior during power toothbrushing with toothpastes with various abrasivities. Part I: wear behavior. J Mater Sci Mater Med. 2008;19(9):3041-8.

13. Espallargas N, Mischler S. Dry wear and tribocorrosion mechanisms of pulsed plasma nitrided $\mathrm{Ni}-\mathrm{Cr}$ alloy. Wear. 2011;270(7-8):464-71.

14. Guangyan QIAO, Jeansheng SU, Meifing H. E. Effect of (-)epigallocatechin gallate on electrochemical behavior and surface film composition of $\mathrm{CoCr}$ alloy used in dental restorations. Dent Mater J. 2012;31(4):564-74.

15. Wylie CM, Shelton RM, Fleming GJ, Davenport AJ. Corrosion of nickel-based dental casting alloys. Dent Mater. 2007;23(6):71423.

16. Rezende MCRA, Alves APR, Codaro EN, Dutra CAM. Effect of commercial mouthwashes on the corrosion resistance of Ti-10Mo experimental alloy. J Mater Sci Mater Med. 2007;18(1):149-54.

17. Okazaki Y, Gotoh E. Comparison of metal release from various metallic biomaterials in vitro. Biomaterials. 2005;26(1):11-21.

18. Bayramoglu G, Alemdaroglu T, Kedici S, Aksüt AA. The effect of $\mathrm{pH}$ on the corrosion of dental metal alloys. J Oral Rehabil. 2000;27(7):563-75.

19. Bezzon OL, Pedrazzi H, Zaniquelli O, Silva TBC. Effect of casting technique on surface roughness and consequent mass loss after polishing of $\mathrm{NiCr}$ and $\mathrm{CoCr}$ base metal alloys: a comparative study with titanium. J Prosthet Dent. 2004;92(3):274-7.

20. Videla HA, Herrera LK. Microbiologically influenced corrosion: looking to the future. Int Microbiol. 2005;8(3):169-80.

21. Guilherme AS, Henriques GEP, Zavanelli RA, Mesquita MF. Surface roughness and fatigue performance of commercially pure titanium and Ti-6Al-4V alloy after different polishing protocols. J Prosthet Dent. 2005;93(4):378-85.

22. Barão VAR, Yoon CJ, Mathew MT, Yuan JC, Sukotjo C. Attachment of Porphyromonas Gingivalis to corroded commercially pure titanium and titanium-aluminium vanadium alloy. J Periodontol. 2014;85(9):1275-82.

23. Molina C, Nogués L, Martinez-Gomis J, Peraire M, Salsench J, Sevilla P, et al. Dental casting alloys behaviour during power toothbrushing with toothpastes of various abrasivities. Part II: corrosion and ion release. J Mater Sci Mater Med. 2008;19(9):3015-9.

24. Hodgson AWE, Kurz S, Virtanen S, Fervel V, Olsson COA, Mischler S. Passive and transpassive behavior of CoCrMo in simulated biological solutions. Electrochim Acta. 2004;49(13):2167-78.

25. Bauer JRO, Grande RHM, Rodrigues-Filho LE, Pinto MM, Loguercio AD. Does the casting mode influence mircrostructure, fracture and properties of different metal ceramic alloys? Braz Oral Res. 2012;26(3):190-6.

26. Hiromoto S, Onodera E, Chiba A, Asami K, Hanawa T. Microstructure and corrosion behavior in biological enviroments of the new forged low-Ni Co-Cr-Mo alloys. Biomaterials. 2005;26(24):4912-23. 